\title{
Learning Method that Facilitates User Understanding of Changes in the Kyoto Townscape: Utilizing a Smartphone Application with the Kyoto City Tram and Bus Photograph Database
}

\author{
Akira Takahashi $^{\text {a, }}{ }^{*}$, Shumpei Yamamoto ${ }^{b}$, Hirotaka Sato ${ }^{b}$, Naomi Kawasumi ${ }^{b}$, Manabu Inoue ${ }^{b}$, Keiji Yano $^{b}$, and \\ Asanobu Kitamoto ${ }^{\text {c }}$ \\ ${ }^{a}$ KWANSEI GAKUIN University, akira.takahashi@kwansei.ac.jp \\ ${ }^{b}$ RitsumeikanUniversity,lt0465xr@ed.ritsumei.ac.jp,lt0114rr@gmail.com,n-kawa@fc.ritsumei.ac.jp,cqa04666@nifty.ne.jp, \\ yano@lt.ritsumei.ac.jp \\ ${ }^{c}$ Center for Open Data in the Humanities, Joint Support-Center for Data Science Research, Research Organization of Information \\ and Systems / National Institute of Informatics, kitamoto@nii.ac.jp \\ * Corresponding author
}

\begin{abstract}
This study intends to develop a method of learning changes in the Kyoto townscape. We conducted an experiment using the Kyoto Memorygraph with old photographs from the Kyoto City Tram and Bus Photograph Database. The key findings of this paper are the following:

- Users can easily understand the details of changes in the townscape when comparing old photographs with the current townscape using Kyoto Memorygraph.

- By using this application in tours, users who were not previously familiar with the locations and characteristics of old photographs exhibited notable learning outcomes.

In this experiment, participants focused on mountains as a distant marker and buildings, roads, and objects on the roadside as proximate markers. These are the basic components of the city; participants examined the structure and elements from the old photos and became aware of changes in the townscape. In the case that the characteristics of the photo had changed significantly, some participants felt it was difficult to match old photos with the current townscape. By visiting the location where the old picture was taken and capturing the current cityscape, users of Kyoto Memorygraph were able to consider the city's structure and elements. These results indicate that Kyoto Memorygraph can be a regional learning tool for understanding townscape development.
\end{abstract}

Keywords: old photographs, townscape, Kyoto City Tram and Bus Photograph Database, Kyoto Memorygraph

\section{Introduction}

Kyoto was less intensely affected by World War II than other cities in Japan; thus, many historic buildings have remained and comprise a historic townscape.

However, the historical Kyoto townscape is gradually being lost because economic growth has taken top priority following the war, and many historic buildings had been demolished due to substantial uniform land development and construction activities. The historical townscape was formed as considering the policy of townscape to better understand its factors and transitions.

In addition to the problem of townscape destruction, there are various issues such as population decrease, rapidly aging population, and decline of local industry.

As the underlying community is gradually weakened, the local residents' active promotion of regional revitalization while cooperating with various stakeholders is necessary (KCCC 2018).
In order to promote distinctive regional formation, it is important for local people to reaffirm the significance of regional resources, such as historic buildings, regional records, and local memories. Some residents have begun trying to become familiar with the landscape.

Old photographs and maps that help people visually comprehend past townscapes are considered to be effective for facilitating the understanding of townscape changes, and digital archives have attracted the attention of various fields, including folklore, history, and geography (Seto \& Yano 2009).

In recent years, the development of information and communication technology (ICT) and the reduced cost of information equipment have generally created an environment in which large amounts of data can be processed efficiently, which provides local residents the ability to discover and archive regional resources.

On the other hand, there are institutional issues such as legal restrictions, copyrights, and portrait rights, which 
protect the proper operation of content, that can hinder flexible secondary use. Other issues include a lack of methods and systems that have been established to collect and archive materials. Furthermore, in the case of old photos taken individually, the shooting location, date, and time may be unknown. Therefore, they may be difficult to use as academic materials, and there are situations in which the use of content does not appreciably progress after archiving.

In this context, it is considered important to systematically find a proper archive of old photographs and use their regional data efficiently.

This study focuses on the Kyoto townscape between 1950s and 1970s and examines the method of learning changes in the townscape by comparing the present landscape with old photographs from the Kyoto City Tram and Bus Photograph Database that is digitally archived and published at the Ritsumeikan University Art Research Center (ARC).

When comparing old photographs with the current townscape, it is considered significant to compare them in the same composition in order to fully comprehend the change. In this study, we implement the smartphone application Kyoto Memorygraph, developed by Kitamoto. The characteristics of Kyoto Memorygraph are detailed in 1.2 .

\subsection{Kyoto City Tram and Bus Photograph Database}

This study focused on old Kyoto Tram photographs to understanding changes in the Kyoto townscape after the war. The reasons for focusing on these photographs are as follows:

- Photographs of railroads, including Kyoto City Trams, are often available in the form of collections, even though personal photographs are not generally available since cameras were not widely used in the 1960s.

- While the railroad car is the subject of the photograph, the townscape of the time is reflected in the background; being able to visualize the landscape of the time is valuable due to the limited access to photographic materials.

- A relatively large number of photographs from the Meiji period to closed in 1978 are left; this especially facilitates the understanding of change in the Kyoto townscape after the war.

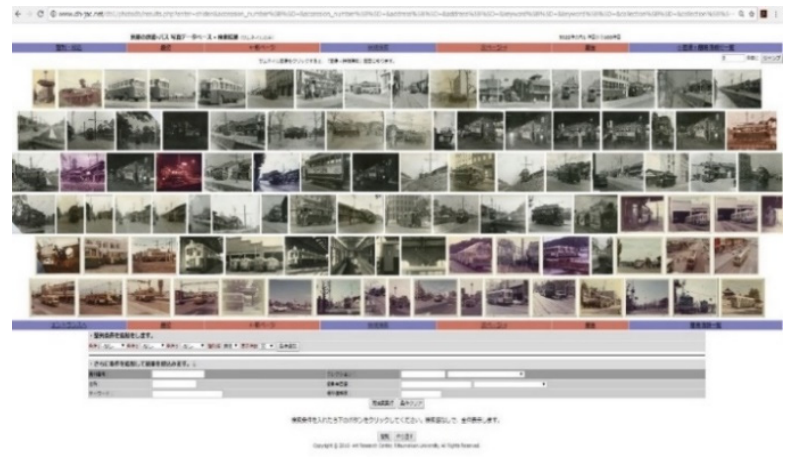

The authors (Yamamoto et al. 2017) have constructed and released the Kyoto City Tram and Bus Photograph Database (KCTDB), which is a digital archive linked to maps, on February 2017 at ARC on the web (Figure 1).

At the time of collecting photographs to comprise the KCTDB, we obtained permission from the owners; furthermore, we examined the identification method for each photograph's location information (Takahashi et al. 2017).

For each photograph in KCTDB, basic information is registered as metadata: ID, source name, address, photograph year, subject, location reliability, owner, collection name. Users are then able to search the database using various information such as the document number, photograph year, and keywords. The photograph location is specified using Google Maps, and the current place can be easily seen by using the "Street View" function (Figure 2).

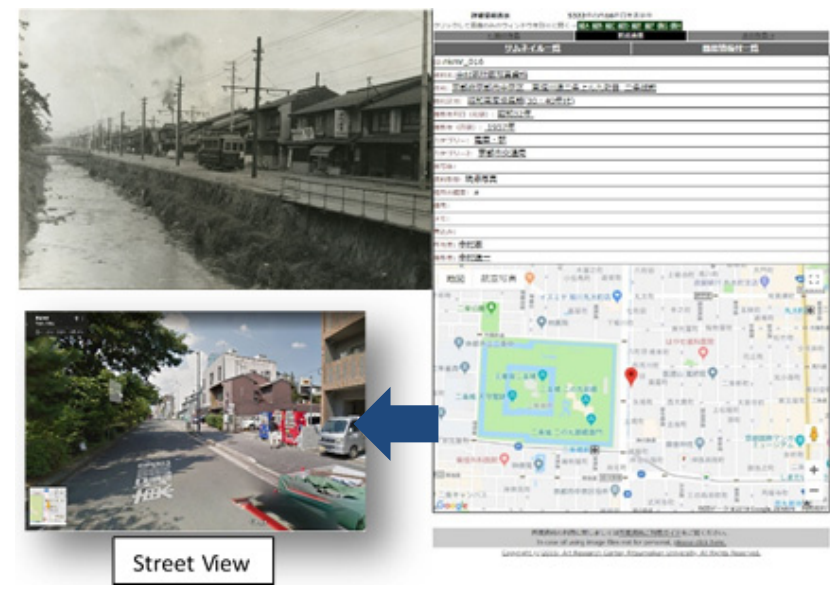

Figure 2. Information of a photograph (KCTDB)

As of March 1 2019, KCTDB has released 5,322 items (6 collections), 3,310 of which specify the photograph position, and there are 2,628 items in which the photograph position is specified in Kyoto City and Keifuku Electric Railway, which only have Kyoto City as their business area (Table 1).

\begin{tabular}{|c|c|c|c|c|}
\hline \multirow{2}{*}{$\begin{array}{c}\text { location } \\
\text { reliability }\end{array}$} & \multicolumn{3}{|c|}{ management companies } & \multirow{2}{*}{ amount } \\
\cline { 2 - 4 } & $\begin{array}{c}\text { Kyoto City Tram } \\
\text { (Kyoto City) }\end{array}$ & $\begin{array}{c}\text { Keifuku } \\
\text { Electric Railroad }\end{array}$ & Other & \\
\hline a (exact) & 2561 & 67 & 682 & 3310 \\
\hline b (near) & 44 & 0 & 0 & 44 \\
\hline c (unknown) & 414 & 164 & 1390 & 1968 \\
\hline amount & 3019 & 231 & 2072 & 5322 \\
\hline
\end{tabular}

Table 1. Location reliability of photographs (KCTDB)

Figure 3 shows the density distribution of 2628 points and the route of Kyoto City Tram between the 1950s and 1970s and Keifuku Electric Railroad.

Figure 1. List of photographs (KCTDB) 


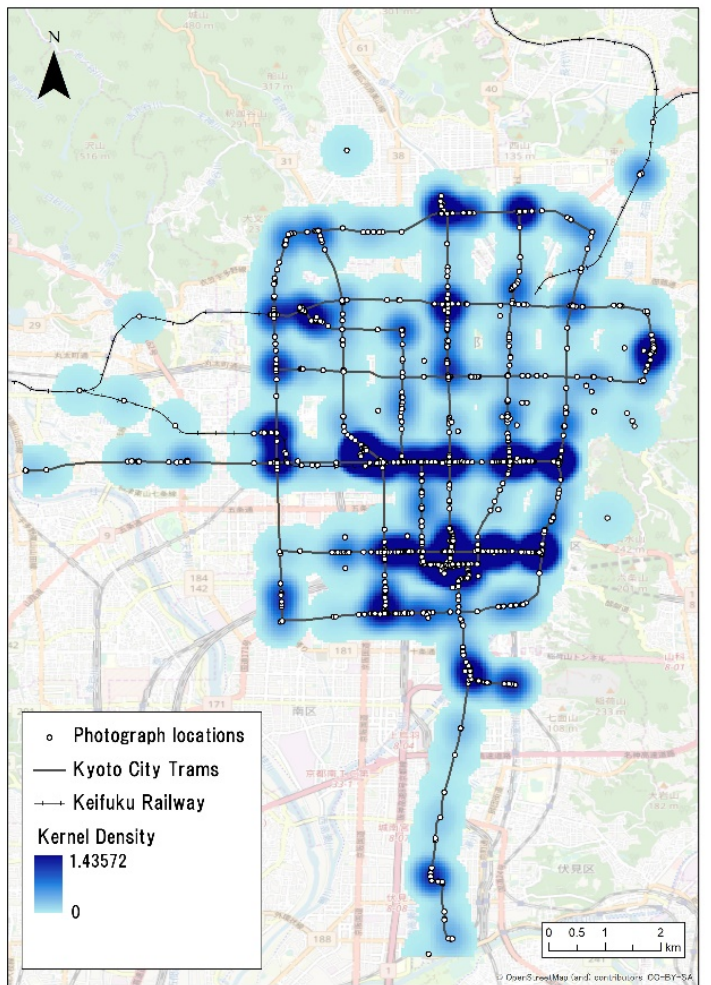

Figure 3. Kernel density distribution of photograph locations (KCTDB)

\subsection{Kyoto Memorygraph}

This study compared old photographs with current landscapes at the same position in order to understand changes in the townscape accurately. We utilized Kyoto Memorygraph (developed by Kitamoto, 2018) to achieve that.

Kyoto Memorygraph is a smartphone application and a new photographic technique to create layers of historical images. Its basic function is accurately capturing photographs at the same place and with the same composition by displaying old photographs as a semitransparent filter on the viewfinder. The map function supports users ability to find the location of old photographs.

The basic usage procedure is as follows (Figure 4):

- Go to the place where the old photograph was taken using the map function.

- Take a photograph at the same angle with the old photograph as a reference on the viewfinder.

- Share the photograph on the application.

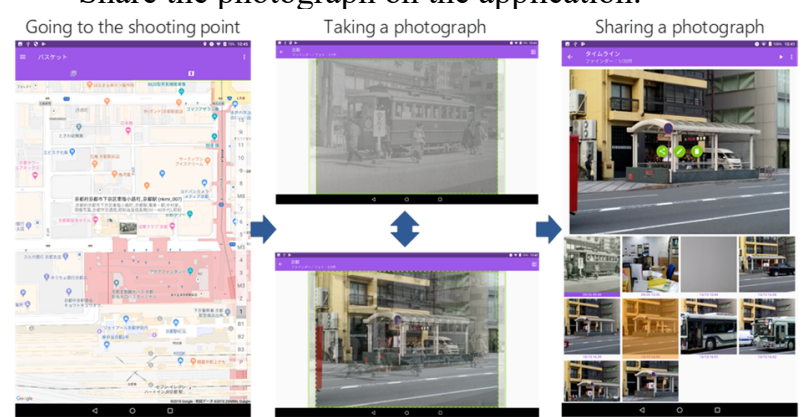

Figure 4. Basic operation of Kyoto Memorygraph
Kyoto Memorygraph has two modes: Project mode, intended for sharing old photographs to be taken with a number of people, and Local mode, intended for using photos taken by an individual. The outline of Project mode, which was the mode employed in this experiment is as follows (Figure 5):

- As preliminary preparation, digital data and metadata (i.e., ID, position information, photographer) of old photographs are prepared in a server, and the data is registered as a project.

- The registered projects can be downloaded from the server of each terminal; many users can use it simultaneously.

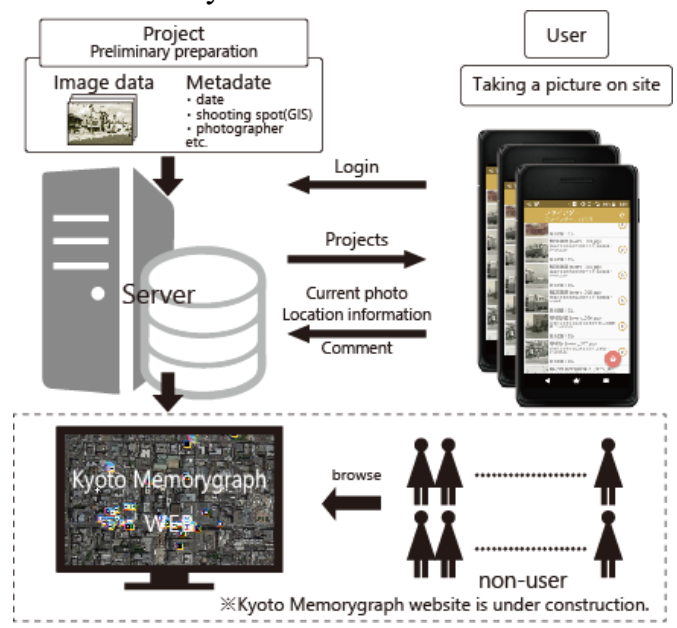

Figure 5. Kyoto Memorygraph, Project mode

\section{Method}

Our experiment consisted of walking around town with Kyoto Memorygraph and conducting questionnaires with participants (Figure 6) and the participants were recruited using a website (Table 2).

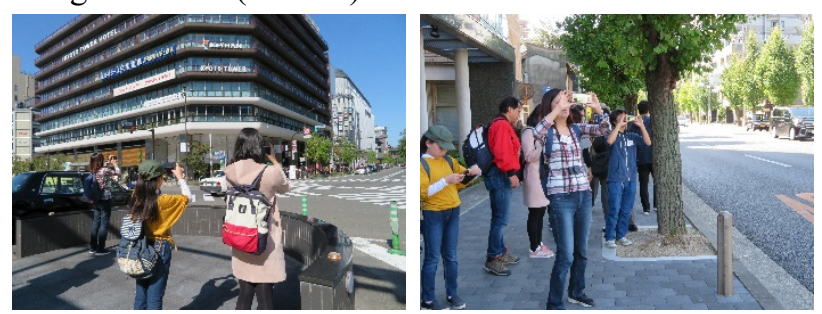

Figure 6. Image of participants taking photographs

\begin{tabular}{|c|c|c|}
\hline Applications a & and inquiries : & : KYOTO KEIKAN FORUM(NPO) \\
\hline Application pe & eriod : : & : 9/27/2018-10/13(extended 10/17) \\
\hline Application me & nethod & : Web form and Telephone \\
\hline Publication & News Paper : & : The Kyoto Shimbun (Morning newspaper 10/13) \\
\hline & Web : & : KYOTO KEIKAN FORUM (NPO) \\
\hline & & https:/kyotokeikan.org/ \\
\hline & & Kyo Manabi Net (Kyoto city Board of Education) \\
\hline & & http://miyakomanabi.jp/ \\
\hline & & Civic activity information sharing portal site (Kyoto Civic Activity Center) \\
\hline & & https://shimisen-kyoto.org/ \\
\hline & & Maipure(Future Link Network Co.,Ltd.) \\
\hline & & https://mypl.net/ \\
\hline & Flyer : & : Kyoto Center for Community Collaboration \\
\hline & & $\begin{array}{l}\text { Kyoto Civic Activity Center } \\
\text { etc. }\end{array}$ \\
\hline Participants & & : without any qualification \\
\hline
\end{tabular}

Table 2. Recruitment method of participants for Kyoto Memorygraph experiment 


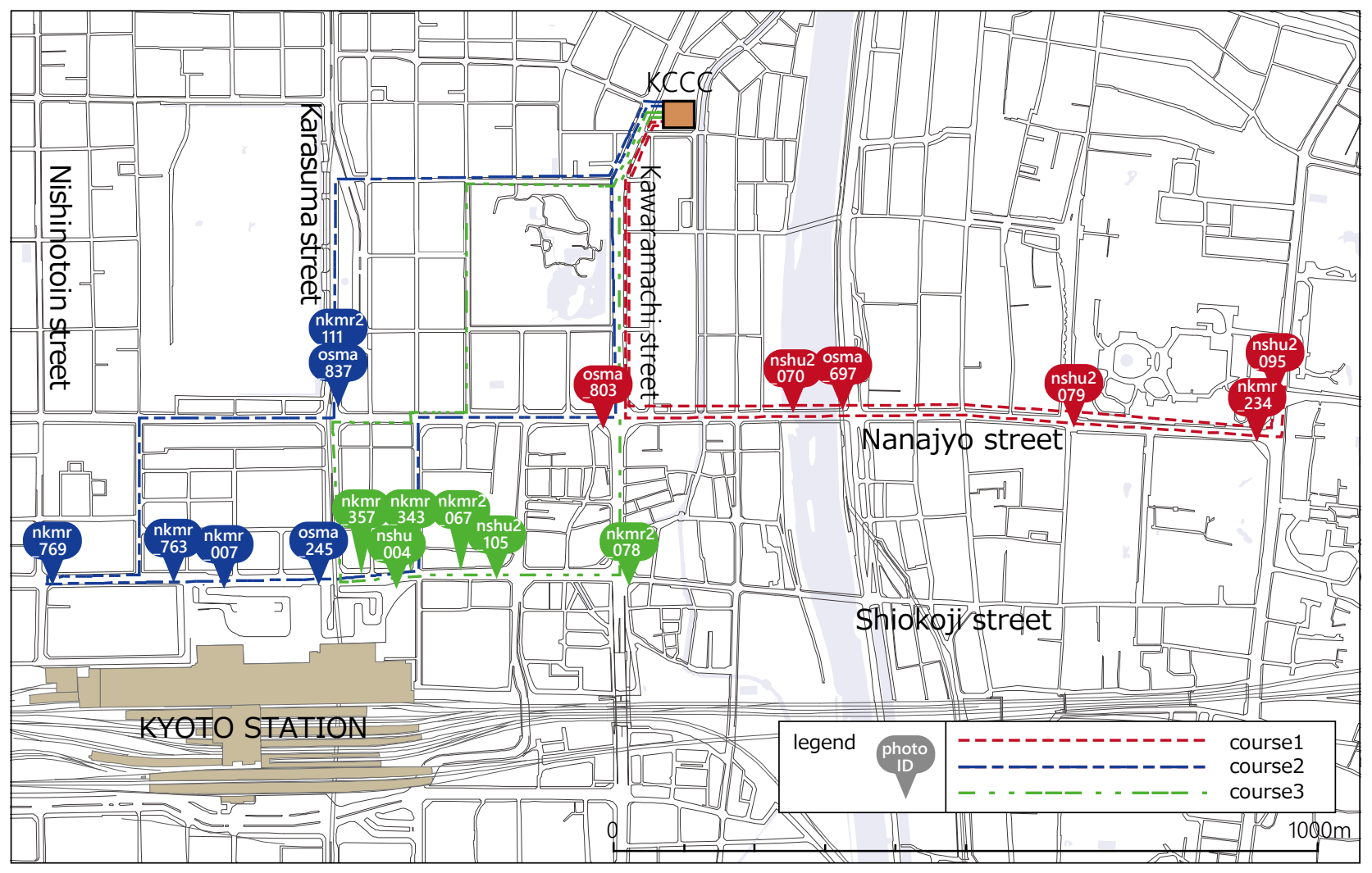

Figure 7. Course and photo spots of the experiment

Table3 shows the overview of the experiment and questionnaire. The experiment was conducted on October 212018 .

\begin{tabular}{|c|c|}
\hline \multicolumn{2}{|r|}{ Experiment } \\
\hline Date & : 21. Oct.2018 \\
\hline \multirow[t]{5}{*}{ Day Schedule } & : 9:00 Opening and Reception \\
\hline & 9:30 Kyoto Memorygraph and tour outline \\
\hline & $\begin{array}{l}\text { 10:30 Experiment tour departure } \\
\text { (courses 1-3, } 6 \text { groups) }\end{array}$ \\
\hline & $12: 30$ End \\
\hline & 14:00 Talk session (joint event) \\
\hline \multirow[t]{3}{*}{ Place } & : Kyoto Center for Community Collaboration(KCCC) \\
\hline & 83-1 Umeminato-cho, Nishi Kiyamachi-dori, \\
\hline & $\begin{array}{l}\text { Kaminokuchi agaru, Shimogyo-ku, Kyoto 600-8127, } \\
\text { Japan }\end{array}$ \\
\hline Participants & : 23 \\
\hline \multicolumn{2}{|r|}{ Questionnaire } \\
\hline Title & : Kyoto Memory graph experiment questionnaire \\
\hline \multirow[t]{3}{*}{ Survey item } & $\begin{array}{l}\text { 1.Particip ant informaiton } \\
\text { 2.About tour }\end{array}$ \\
\hline & 3.About usage of apprication \\
\hline & 4.About Memory graph(Overlay of photos) \\
\hline Answer & : $23(100 \%)$ \\
\hline
\end{tabular}

Table 3. Content of Kyoto Memorygraph experiment

The number of participants was 23 , and the questionnaire collection rate was $100 \%$. The details of the experiment are as follows:

- The participants were organized into six groups of 35 participants and 2 staff members.

- Before the experiment, participants were taught how to use Kyoto Memorygraph.
- After that, the participants had the opportunity to use Kyoto Memorygraph by taking photographs around $\mathrm{KCCC}$.

- Three different courses were set up. KCCC was the start and goal for each course, and the walking distance was about $2.5 \mathrm{~km}$. The course was intended to be finished in 2 hours (Figure 7).

- In each course, participants targeted 6 old photos selected from KCTDB to match locations in the course.

- After arriving at the photograph location, participants searched for the photograph angle for about 5 minutes. After 5 minutes, the staff showed the photograph angle to participants who were unable to find it.

- Participants were asked to complete the questionnaire after the tour.

The questionnaire included items that collect participant information and information about the tour, app, and what participants focused on when taking photos.

\section{Results and discussions}

\subsection{Participants information}

Figure 8 outlines the participants' demographic information: $39 \%$ of participants were teenagers, $22 \%$ were in their $60 \mathrm{~s}$, and $13 \%$ were in their $70 \mathrm{~s}$ and over. There were few participants in their 20s and 30s. Of all the participants, $39 \%$ were students, $22 \%$ were self-employed, 
and $17 \%$ were traditionally employed.

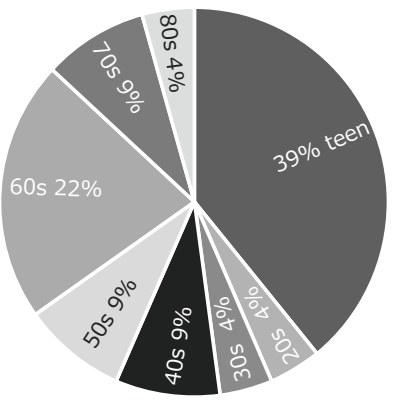

Age group

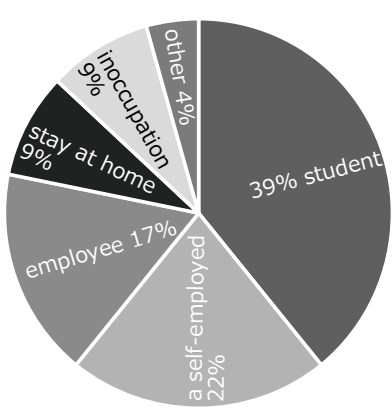

Work
Figure 8. Information of the participants $(\mathrm{N}=23)$

\subsection{About the Tour}

Table 3 shows the results of participants' satisfaction by age, derived from the questionnaire item "How was the tour?" The results indicate that satisfaction was high regardless of age, and $82.6 \%$ of participants answered that they were satisfied. No participants reported dissatisfaction.

\begin{tabular}{|c|c|c|c|c|c|}
\hline & $\begin{array}{c}\text { extremely } \\
\text { satisfied }\end{array}$ & satisfied & $\begin{array}{c}\text { neither } \\
\text { satisfied } \\
\text { nor } \\
\text { dissatisfied }\end{array}$ & $\begin{array}{c}\text { no } \\
\text { answer }\end{array}$ & total \\
\hline $10 \mathrm{~s}$ & 1 & 8 & & & 9 \\
\hline $20 \mathrm{~s}$ & & 1 & & & 1 \\
\hline $30 \mathrm{~s}$ & & 1 & & & 1 \\
\hline $40 \mathrm{~s}$ & 1 & 1 & & & 2 \\
\hline $50 \mathrm{~s}$ & 1 & & 1 & & 2 \\
\hline $60 \mathrm{~s}$ & 1 & 2 & 2 & & 5 \\
\hline $70 \mathrm{~s}$ & & 1 & & 1 & 2 \\
\hline $80 \mathrm{~s}$ & & 1 & & & 1 \\
\hline total & 4 & 15 & 3 & 1 & 23 \\
\hline
\end{tabular}

Table 3. Satisfaction of the tour: "How was the tour?"

Table 4 shows the results of the tour duration by age, derived from the questionnaire item "How did you feel about the tour time?" The results indicate that $69.6 \%$ of the participants felt that the tour was "neither short nor long." Although this study examined a small sample, older people felt that time of the tour was shorter, and younger people tended to feel longer.

Some participants hoped that the tour was going to be conducted in a familiar place. One participant commented: "I hope it is held where I always go around buildings I know well." (10s), and one elderly participant commented: "l hope it is held in areas with many memories." (70s) Moreover, some participants liked that there was an explanation about the townscape in old photographs from the staffs. One participant commented: "I enjoyed going around with the guide and listening to something I didn't know. It's nice to go around with the guide." (40s) and another commented: "I would like to go around in various places in Kyoto while watching the change with the guide and this app." (70s).

\begin{tabular}{|c|c|c|c|c|c|c|}
\hline & $\begin{array}{l}\text { very } \\
\text { short }\end{array}$ & $\begin{array}{l}\text { quite } \\
\text { short }\end{array}$ & $\begin{array}{c}\text { neither } \\
\text { short } \\
\text { nor } \\
\text { long... }\end{array}$ & $\begin{array}{r}\text { quite } \\
\ldots \text { löning }\end{array}$ & $\begin{array}{l}\text { very } \\
\text { "long }\end{array}$ & total \\
\hline $10 \mathrm{~s}$ & & & 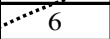 & 2 & $1 \vdots$ & 9 \\
\hline $20 \mathrm{~s}$ & & 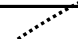 & 1 & & 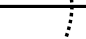 & 1 \\
\hline $30 \mathrm{~s}$ & & & & 1 & 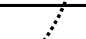 & 1 \\
\hline $40 \mathrm{~s}$ & $\therefore$ & & 2 & & & 2 \\
\hline $50 \mathrm{~s}$ & & & 2 & & & 2 \\
\hline $60 \mathrm{~s}$ & 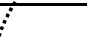 & 2 & 3 & $.0^{\circ}$ & & 5 \\
\hline $70 \mathrm{~s}$ & 1 & & 1 & $9^{\circ}$ & & 2 \\
\hline $80 \mathrm{~s}$ & $\because$ & & $\ldots \ldots \cdot 1^{* *^{*}}$ & & & 1 \\
\hline $\begin{array}{c}\text { total } \\
(\%)\end{array}$ & $\begin{array}{l}1 \cdots \\
4.3 \%\end{array}$ & $\begin{array}{l}\cdots \cdot 2 . \cdots \\
8.7 \%\end{array}$ & $\begin{array}{c}16 \\
69.6 \%\end{array}$ & $\begin{array}{c}3 \\
13.0 \%\end{array}$ & $\begin{array}{c}1 \\
4.3 \%\end{array}$ & $\begin{array}{c}23 \\
100.0 \%\end{array}$ \\
\hline
\end{tabular}

Table 4. Time of the tour: "How did you feel about the tour time?"

\subsection{About the Application}

Table 5 shows the results of the usability of the application by age, derived from the questionnaire item "Was it difficult to use the application?" The results indicate that $34.8 \%$ of the participants believed that using the app was "neither easy nor difficult." Younger users are less likely to find it difficult because they are "used to it" (10s), but there some barriers for older users. No participants answered that it the app was easy to use. One participant commented "I have never used a smartphone" (70s), and the other commented: "The display sometimes changes when I touch the screen" (60s).

\begin{tabular}{|c|c|c|c|c|c|c|}
\hline & $\begin{array}{c}\text { very } \\
\text { eassy.... }\end{array}$ & $\begin{array}{c}\text { quite } \\
\cdots \text { easy..... }\end{array}$ & $\begin{array}{c}\text { neither } \\
\text { easy } \\
\text { nor } \\
\text { difficult } \\
\end{array}$ & $\begin{array}{c}\text { quite } \\
\text { difficult }\end{array}$ & $\begin{array}{c}\text { very } \\
\text { difficult }\end{array}$ & total \\
\hline $10 \mathrm{~s}$ & $\because 1$ & 4 & $4 \cdot \cdots$ & & & 9 \\
\hline $20 \mathrm{~s}$ & & 1 & & ${ }^{\bullet} \bullet \bullet \bullet$ & & 1 \\
\hline $30 \mathrm{~s}$ & $\because$ & & & $1 \bullet$ & & 1 \\
\hline $40 \mathrm{~s}$ & & & 2 & & & 2 \\
\hline $50 \mathrm{~s}$ & & & & 1 & 1 & 2 \\
\hline $60 \mathrm{~s}$ & & ${ }^{\ddots} \bullet \bullet$ & 1 & 2 & 2 & 5 \\
\hline $70 \mathrm{~s}$ & & & 1 & & 1 & 2 \\
\hline $80 \mathrm{~s}$ & & & $\cdots \cdots$ & 1 & $\therefore$ & 1 \\
\hline total & $\begin{array}{l}1 \\
4.3 \%\end{array}$ & \begin{tabular}{|c|}
5 \\
$21.7 \%$ \\
\end{tabular} & \begin{tabular}{|c|}
8 \\
$34.8 \%$ \\
\end{tabular} & $\begin{array}{c}5 \\
21.7 \% \\
\end{array}$ & $\begin{array}{c}4 \\
17.4 \%\end{array}$ & $\begin{array}{c}23 \\
100.0 \%\end{array}$ \\
\hline
\end{tabular}

Table 5. Usability of the application: "Was it difficult to use the application?"

Table 6 shows the results of participants' satisfaction of the application, derived from the questionnaire item "Was it fun to use the application?" The results indicate that $65.2 \%$ of the participants were "satisfied" with the application. One elderly participant felt that it was difficult to operate the app, but he was "satisfied" and commented: "When I saw the picture of the old train, I remembered that I went to school in my school days" (80s). In addition, others commented: "changes in the city can be compared" (70s), "I felt the connection between the past and the present." (50s), and "Not only passing by, but also taking a photo and I could see the town from another perspective by comparing with photos." (50s). On the other hand, some participants made negative comments: "I had a hard time working on the operation method, so I couldn't get to the 
point where I could really understand the fun." (60s), "I still do not understand the meaning of comparison with photos" (70s) and "It was difficult to do the operation with transparency." (60s).

\begin{tabular}{|c|c|c|c|c|c|c|}
\hline & $\begin{array}{c}\text { extremely } \\
\text { satisfied }\end{array}$ & satisfied & $\begin{array}{c}\text { neither } \\
\text { satisfied } \\
\text { nor } \\
\text { dissatisfied }\end{array}$ & dissatisfied & $\begin{array}{c}\text { extremely } \\
\text { dissatisfied }\end{array}$ & total \\
\hline $10 \mathrm{~s}$ & 1 & 6 & 2 & & & 9 \\
\hline $20 \mathrm{~s}$ & & 1 & & & & 1 \\
\hline $30 \mathrm{~s}$ & & 1 & & & & 1 \\
\hline $40 \mathrm{~s}$ & 1 & 1 & & & & 2 \\
\hline $50 \mathrm{~s}$ & 1 & & & & 1 & 2 \\
\hline $60 \mathrm{~s}$ & & 1 & 1 & 2 & 1 & 5 \\
\hline $70 \mathrm{~s}$ & & 1 & & 1 & & 2 \\
\hline $80 \mathrm{~s}$ & & 1 & & & & 1 \\
\hline total & 3 & 12 & 3 & 3 & 2 & 23 \\
& $13.0 \%$ & $52.2 \%$ & $13.0 \%$ & $13.0 \%$ & $8.7 \%$ & $100.0 \%$ \\
\hline
\end{tabular}

Table 6. Satisfaction of the application: "Was it fun to use the application?

The usability of the application was not a problem for younger participants, whereas older participants believed either that the app could be usable if they became familiar with it or that the app had poor usability. Some participant's opinions suggested that using the app is fun because it is possible to visualize changes in landscape.

\begin{tabular}{|c|c|c|c|c|c|c|c|}
\hline & $\begin{array}{c}\text { past } \\
\text { lifestyle }\end{array}$ & $\begin{array}{c}\text { transition } \\
\text { of } \\
\text { townscape }\end{array}$ & $\begin{array}{c}\text { change } \\
\text { of city } \\
\text { structure }\end{array}$ & $\begin{array}{c}\text { change } \\
\text { of } \\
\text { vehicle }\end{array}$ & $\begin{array}{c}\text { Inter- } \\
\text { generational } \\
\text { exchange }\end{array}$ & $\begin{array}{c}\text { regional } \\
\text { learning }\end{array}$ & $\begin{array}{c}\text { Multiple } \\
\text { answers) } \\
\text { total }\end{array}$ \\
\hline $10 \mathrm{~s}$ & 1 & 6 & 5 & 4 & 2 & 4 & 22 \\
\hline $20 \mathrm{~s}$ & & 1 & 1 & & 1 & & 3 \\
\hline $30 \mathrm{~s}$ & & & 1 & & & & 1 \\
\hline $40 \mathrm{~s}$ & 1 & 2 & 1 & 2 & 1 & 2 & 9 \\
\hline $50 \mathrm{~s}$ & 1 & 2 & 1 & 1 & & 1 & 6 \\
\hline $60 \mathrm{~s}$ & 2 & 5 & 3 & 2 & 2 & 3 & 17 \\
\hline $70 \mathrm{~s}$ & & 1 & & & & 1 & 2 \\
\hline $80 \mathrm{~s}$ & 1 & & 1 & & & & 2 \\
\hline $\begin{array}{c}\text { total/N=23 } \\
(\%)\end{array}$ & 6 & 17 & 13 & 9 & 6 & 11 & 62 \\
\hline
\end{tabular}

Table 7. Purpose of using the application: "What do you think this app will be helpful for? (Multiple answers allowed)

Table 7 shows the participants' perspective of the purpose of the application, derived from the questionnaire item "What do you think this app will be helpful for? The results indicate that $73.9 \%$ of participants believe that the app will be helpful in demonstrating the "transition of the townscape" and $56.5 \%$ believe it will be helpful in showing "changes in city structure."

\subsection{About Kyoto Memorygraph (Overlay of photos)}

Figure 9 shows example answers regarding Kyoto Memorygraph (overlay of photos) for the participants. The participants evaluated "the difficulty of finding the photograph location" and "the difficulty of finding the photograph angle" on a five-point scale, and they reported "the points that they focused on while taking a photo." Table 8 shows the answers of the participants about Kyoto Memorygraph (Overlay of photos). Illustrations and comments were grouped according to similarity. The results indicate that the subjects were primarily mountains, buildings (landmarks, temples, shrines, and town houses), roads (streets, paths, and bridges), and objects on the roadside (power poles and signals).

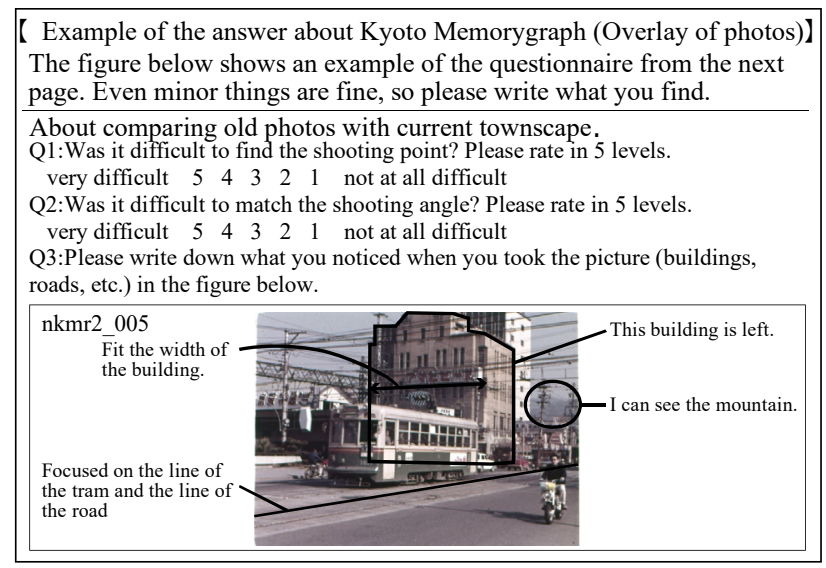

Figure 9. Example answer regarding the use of Kyoto Memorygraph (Overlay of photos)

Some participants highlighted mountains out as big hint for taking photos in the case of NO2 and NO3, and they commented: "I compared my photo with the mountain." "Evaluation of the difficulty of the photograph location" (EL) and "Evaluation of the difficulty of the shooting angle" (EA) were relatively low.

Some participants focused on buildings it to match their camera angle with the old photographs and commented: "This building was left" and "I tried to fit the edge of this building." Temples, townhouses, and modern architecture that remained were recognized as important clues that helped participants compare old photos with the current townscape. On the other hand, some participants felt it was difficult to take a picture when characteristic buildings disappear, such as in NO4. One participant commented: "This building was gone, so I felt there was no way to match the scenery."

In NO3, the river became a closed conduit, and some participants commented: "The river was culvert and I could not find it at all." In addition, in NO12, the road had been widened, and most of the participants felt it was difficult to match the photograph angle, leading to an EA value of 4.25. One participant commented: "I couldn't match this photo at all." In cases in which the characteristics of the photo has changed significantly, some participants felt it was difficult to match the current townscape and old photographs.

Participants focused on the structure and elements of the landscape such as mountains, buildings, and roads from the old photos and became aware of changes in the townscape.

\section{Conclusion}

This study intends to develop a method by which people can understand changes in the Kyoto townscape. We conducted experiments on using Kyoto Memorygraph with old photographs from the Kyoto City Tram and Bus 


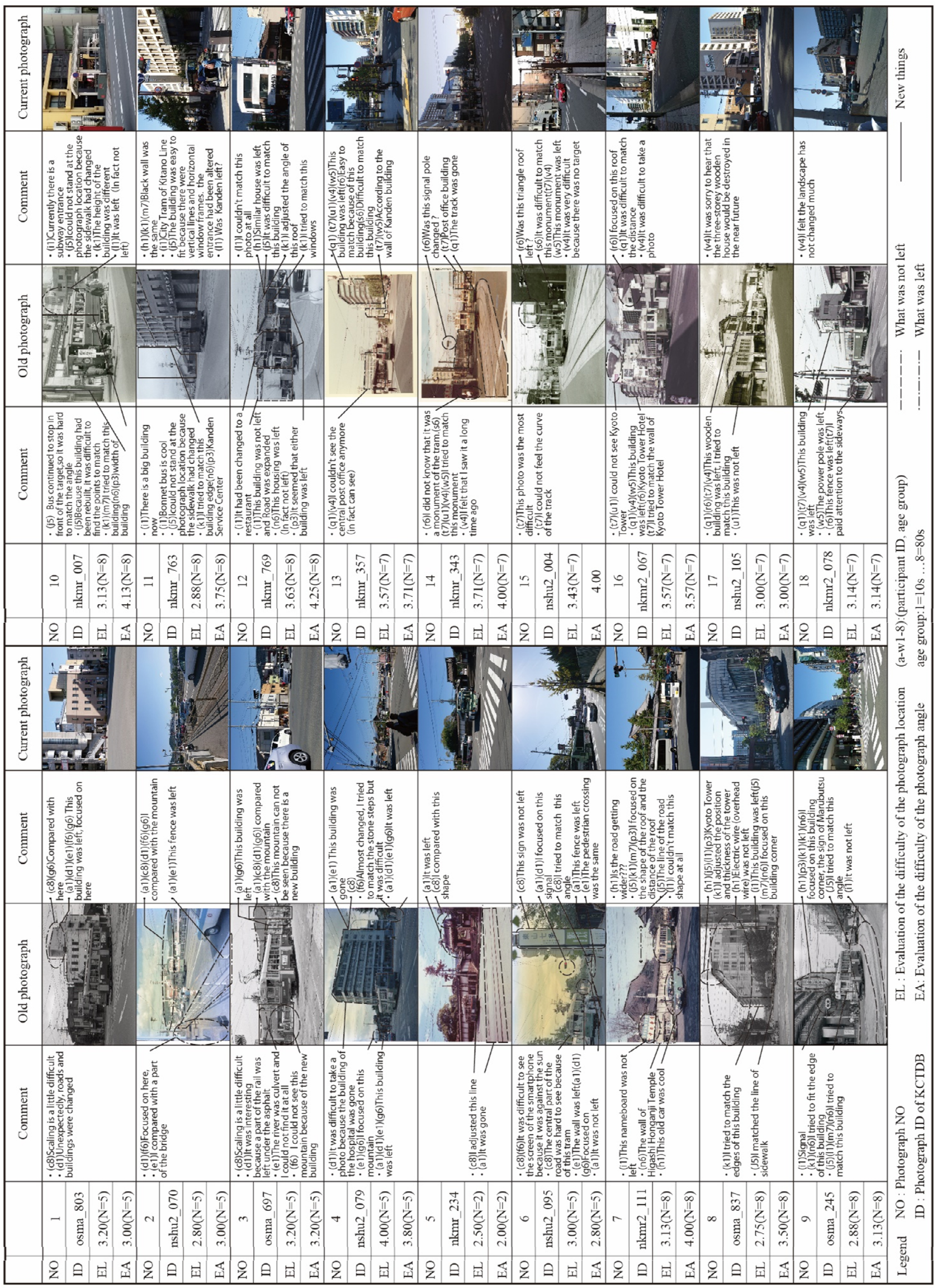

Table 8. Participants' responses regarding the use of Kyoto Memorygraph (Overlay of photos) 
Photograph Database and evaluated it. This study yielded several key findings:

- It is suggested that it is easy to understand the details of changes in the townscape by comparing old photographs with the current townscape using Kyoto Memorygraph.

- By using this application during a tour, users who did not have prior knowledge of the locations of old photographs exhibited notable learning effects.

In this experiment, participants focused on mountains as distant markers and buildings (landmarks, temples and shrines, and town houses), roads (street, path, and bridges) and objects on the roadside (power poles and signals) as proximate markers. These are the basic components of the city; participants examined structures and elements from old photos and became aware of changes in the townscape. In the case that the characteristic features of the photo had changed significantly, some participants felt it was difficult to match the old photo and current townscape. By visiting the place where the old picture was actually taken and taking a picture of the current townscape, users of Kyoto Memorygraph were able to deeply examine the city's structure and elements.

Our results indicate that Kyoto Memorygraph can be an effective regional learning tool.

\section{Acknowledgements}

We are grateful to the members of Railway and Bus Archive Study Group in Kyoto and KYOTO KEIKAN FORUM (NPO). This work was supported (in part) by ROIS-DS-JOINT (007RP2018) and by The Digital Archive Research Center for Japanese Cultural Resources FY 2018 Joint Research Projects at Art Research Center, Ritsumeikan University. We would like to thank Editage (www.editage.jp) for English language editing.

\section{References}

Kyoto City Tram and Bus Photograph Database at Art Research Center, Ritsumeikan University (http://www.dh-jac.net/db1/photodb/search_shiden.php)

Kyoto Center for Community Collaboration. (2018). 20 years of history and the future 20th anniversary magazine.

Kitamoto, A. (2018). Kyoto Memorygraph (https://play.google.com/store/apps/details?id=jp.ac.rois. codh.kyotomemorygraph\&hl=ja)

Seto, T. and Yano, K. (2009). On restoration of historical urban landscape by digitalizing photography resources. Proceeding of SIG Computers and the Humanities (IPSJ Symposium Series), vol.2009 no.16, pages 339-344.

Takahashi, A., Kawasumi, N., Yano, K., Yamaji, M., Yamamoto, S., Sato, H., Imamura, S. (2017). A Study on a Method to Identify the Geographic Information of Old Pictures of Kyoto City Trams by Using the Crowdsourcing System. Papers and Proceedings of the Geographic Information Systems Association 26, page 4 (CD-ROM).
Yamamoto, S., Sato, H., Takahashi, A., Kawasumi, N., Inoue, M., and Yano, K. (2017). GIS-based Digital Archive of Old Photographs and its Utilization: Constructing "Database of Tramways and Buses in Kyoto" Proceeding of SIG Computers and the Humanities (IPSJ Symposium Series), vol.2017 no.2, pages 199-206. 